\title{
Research on the Teaching of professional Japanese in Colleges and Universities under the Network Environment
}

\author{
Ni Jiang \\ Dalian Neusoft University of Information Dalian 116023, China \\ jiangnidl@126.com
}

Keywords: Network; Japanese Teaching; Perfect Measures

\begin{abstract}
After entering the twenty-first Century, Internet presents a leaping development trend, which has affected all aspects of people's lives. Especially for college education, Internet not only makes the classroom more colorful, but also broadens the students' learning channels, which has a positive significance for the improvement of the quality of teaching. Therefore, this paper takes college Japanese teaching as the main body, first analyzes the current situation of the network development in China, and studies the significance of the introduction of Internet in the teaching of professional Japanese and the influence of Internet on the teaching of Japanese in colleges and universities. Finally, it discusses the perfect measures for the teaching of Japanese professional Japanese under the network environment. The combination of professional Japanese teaching and Internet in colleges and universities provides some reference.
\end{abstract}

\section{Introduction}

After entering the twenty-first Century, the development of Internet is far beyond the imagination of people. It has affected every aspect of the society. In particular, mobile phones and computers and other terminal technology, people can be very convenient to enjoy the services of the Internet, greatly changed the way people live. From the specific data, the number of Internet computers in China in 2005 is 50 million, but in 2010, the number of computers on the Internet broke through 10 million. Moreover, social institutions and schools have also optimized their work through the Internet, and have built their own websites. Compared with the traditional information carrier, the advantages of the Internet are very obvious. First of all, information carrying capacity is large enough to meet diversified and personalized needs. Secondly, the Internet has stronger timeliness, better interactivity and lower running cost. All these factors make the Internet more and more popular. For colleges and universities, it has been targeted to explore distance education, so that students can learn knowledge from home, which has greatly changed the mode and direction of education. From the current actual situation, the future development of the Internet will become faster and faster, and the field of penetration will further widen.

\section{Significance of the introduction of the Internet in the teaching of professional Japanese in Colleges and Universities}

\subsection{Training practical talents}

The basic purpose of teaching Japanese majors in universities is to train cross-cultural communication talents, and more importantly, to cultivate students' practical ability. But from the view of traditional teaching, teachers are more indifferent to instillation and instillation of knowledge, lack of independent exploration of students, and the assessment is very simple, and the comprehensive ability of the students can not be better reflected. But in the Internet mode, the College Japanese teaching completely subverts the traditional classroom. First of all, it can provide the students with massive resources to meet the needs of different students, and then enrich the content of the classroom, so that the teaching should pay more attention to practice and exploration. In this mode, students' personal ability has been greatly improved, and they will also enhance their 
personal ability in continuous practice and exploration. Especially in the application of Japanese, students get good exercise. Therefore, the introduction of the Internet to professional Japanese Teaching in Colleges and universities can cultivate more practical talents, so that teaching can meet the needs of the society.

\subsection{Optimizing the mode of teaching}

The traditional teaching mode of our country has some disadvantages. It pays too much attention to the teacher's dominant position in the classroom. Students are more passively inculcated by knowledge and lack of self-learning ability. For Japanese majors in Colleges and universities, daily teaching is rather boring, and the basis of learning is poor, many students lack interest and the teaching effect is not good. But introducing the Internet into professional Japanese Teaching in Colleges and universities can change this problem very well, and effectively optimize the teaching mode. After the goal of teaching is determined, a large number of resources can be introduced through the Internet, with specific situational patterns and vivid teaching images, which can improve the students' enthusiasm for learning. Before the beginning of teaching, teachers can first introduce a video into teaching, and then give specific questions, which are explored independently by students. In particular, with the addition of context, students can better understand the knowledge points, and the group cooperation model also increases the impression of the students, so it can effectively improve the effect of teaching.

\subsection{Conforms to the needs of the development of the times}

Education is not the same thing. If we want to do well in the transmission of knowledge and the cultivation of talents, we must constantly combine the needs of the times. Especially for the institutions of higher learning, they represent the advanced productivity, bear the burden of cultivating the talents for the motherland, and grasp the direction of the social development, constantly make mode adjustment and the introduction of new technology, in order to effectively play their role. From the current situation of China, the application of the Internet in the school has become inevitable. The introduction of the Internet into Japanese teaching can not only improve the teaching quality, but also improve the whole teaching mode. It has a positive significance for the improvement of the school education system. Therefore, the teaching of Japanese majors in Colleges and universities should speed up their own footsteps, apply the Internet and multimedia in teaching flexibly, and then find out problems and improve problems in practice, and cultivate more Japanese professional talents.

\section{The influence of Internet on Japanese Teaching in Colleges and Universities}

The influence of the network has penetrated all walks of life, and the education has also been greatly impacted. The traditional teaching mode has been unable to meet the needs of the society and needs to be reformed under the new situation. At present, many colleges and universities have carried out the mode of network teaching, and network teaching has been used as a supplement and supplement to classroom teaching. As for professional Japanese Teaching in Colleges and universities, combined with its own particularity, network education plays a greater role than other majors. Because most students learning Japanese are zero basis, and Japanese learning needs to be based on Japanese culture. Traditional classroom explanation is difficult to let students understand Japanese culture, and the lack of practice and language training will affect the quality of teaching. With the continuous development of the Internet, College Japanese teaching is more convenient. On the one hand, it can get a lot of teaching resources from the network. On the other hand, it can make teaching more vivid and intuitive through multimedia. Specifically, the impact of the Internet on Japanese Teaching in universities is mainly reflected in the following aspects.

\subsection{Changes in the status of Teachers}

The Internet and multimedia have built up a better environment for students' learning. Students are no longer passive accepting knowledge instilling, and more knowledge is explored on the basis 
of theory. Therefore, the status of teachers has changed obviously. In the teaching of Internet mode, teachers are no longer a constant teaching mode, but make teaching content flexibly according to the teaching objectives. Generally, teachers create external situations and formulate learning strategies, and then guide students constantly, and more effective "teach students in accordance with their aptitude". At this time, teachers' identity is gradually transformed from teaching authority to tutorship and facilitator of students' study.

\subsection{Changes in the status of students}

In the teaching of Japanese in Internet based universities, students have become the dominant part of the classroom. Therefore, the students' learning status has changed obviously. On the basis of teaching goals, students can choose the direction of learning more independently, although there are certain challenges, but it is very favorable for the long-term development of the students. In this mode, students need to make rational use of Internet resources, and enhance mutual help and cooperation among students to explore and learn together.

\subsection{Changes in teaching materials and teaching content}

Under the Internet mode, the teaching of Japanese in Colleges and universities pays more attention to the cultivation of students' personal abilities, so the teaching materials and teaching contents have changed greatly. First of all, textbooks are no longer fixed. Teachers will develop more flexible textbooks according to students' personal abilities and actual needs. Secondly, the teaching content is no longer partial to the explanation of the knowledge point, and more is practical application, allowing students to constantly improve their personal abilities through watching video, understanding context and exchanging dialogue and so on. Of course, this change requires higher teachers and increases the workload of teachers. But this has become the development trend of professional Japanese Teaching in Colleges and universities. Colleges and universities should speed up the construction of this area and effectively promote the reform of teaching.

\subsection{Changes in the model of assessment}

Since the use of the Internet is more flexible in College Japanese teaching, the corresponding assessment methods should be changed, and the unified model can not be used to assess all the students. In the new teaching mode, the assessment should pay more attention to the flexible application of knowledge, because the basic purpose of Japanese learning is to make students become cross-cultural communicative talents of Japanese, so the content of assessment should be more focused on this aspect. First, the percentage of written examination will be significantly reduced, followed by increasing situational dialogues and application, and testing students' learning effect with practice. At present, many colleges and universities have made efforts to facilitate this, and have initially explored the corresponding mode, which is of positive significance for the improvement of Japanese teaching.

\section{Measures to improve Japanese Teaching in Colleges and Universities under the network environment}

\subsection{The application of teachers' teaching process}

Under the network environment, Japanese Teaching in Colleges and universities pays more attention to the cultivation of students' thinking ability and the cultivation of practical ability. Therefore, teaching methods should be biased. First of all, we should make use of the resources of the network to make students understand the context and culture of Japanese in many aspects. Secondly, it is necessary to make a fine talk about the key knowledge and the common confusion of the students. Finally, the students can improve their ability in practice and thinking. Generally speaking, the content of College Japanese teaching mainly includes translation, listening, national explanation, dialogue, intensive reading and so on. It is necessary to introduce the network according to the actual needs. For example, in the dialogue, you can first let the students practice their own, and then compare the standard video pronunciation, the teacher to explain, so that the 
students can be more profound understanding of their own improvement. After the conclusion, you can find a lot of Japanese video dialogues in related situations, so that students can understand the specific dialogue application. Video data can start from many directions such as animated cartoon, movie and animation, so that not only can attract students' interest, but also make the coverage of knowledge wider.

For the introduction of some problems, we can find specific situation patterns directly from the network. First, let the students find out the problems in thinking, and then guide the students to carry on the group discussion. Or teachers give a certain direction, let students use the Internet to find the results, so that the classroom teaching can be more vivid and vivid, but also help to deepen the impression of the students, to improve the effect of teaching is very favorable. For homework checking, we can also simplify the work of teachers and meet the needs of students through the network mode, such as mailboxes, forums and so on, can effectively simplify the work of teachers, and also meet the individual needs of the students.

\subsection{The application of students' learning process}

Students' learning can best reflect the value of the Internet. The specific applications are as follows:

(1) Preview before class. Pre class preview is very important for improving the teaching effect. The syllabus can be sent to every student through the network by the teacher, and then the students can learn in advance according to the content to be studied. Through the Internet, students can fully understand the knowledge points, and can also understand their doubts in advance, so that in the follow-up classroom learning is more targeted.

(2) Classroom learning. Classroom learning is mainly through the Internet to understand the context, under the guidance of teachers to practice. At this point, we can compare with our own understanding. If there are still problems, we can ask teachers for further understanding.

(3) Review after class. Teachers will make courseware according to the content of teaching, which is a tool for auxiliary teaching. Under the Internet mode, teachers can share courseware, allowing students to review after class. Because students' personal ability is different, the effect of learning is different, and the time of classroom is very limited, so reviewing after class is very necessary. Through the Internet, students' after-school learning is more convenient, and there are problems that can be communicated with teachers through the network, so that the solution of problems is more timeliness.

\subsection{The application of performance assessment}

The application of network is more effective for the assessment of Japanese majors. First of all, the written examination can be realized online, and the students' online answers are no longer restricted by time and space, and the teachers can use computer aided examination papers to make the assessment more fair and simple. For oral tests, we can also carry out video dialogues according to specific situations and achieve long distance examinations. Of course, there are many improvements in this application, and we need to explore optimization measures in constant practice. But this kind of performance assessment is more individualized, and even can ensure that each student's examination content is different in the condition of the knowledge point, and the education of the western countries is very similar.

\section{Conclusions}

There are obvious differences between the teaching of Japanese and English Teaching in Colleges and universities, because most of the students have the foundation of English and have their own understanding in the long time. But Japanese students have a lot of almost zero basis, if the traditional teaching model, students will lack of interest in learning, and can not cultivate practical talents. Therefore, in combination with the current practical needs, the Internet has gradually introduced into the teaching of Japanese majors in Colleges and universities, and uses a more vivid model to show the Japanese culture, at the same time, to cultivate the students' ability to 
explore independently, and to improve the students' oral Japanese ability in practice and communication. Based on this, this paper, based on the actual situation of Chinese colleges and universities, explores the combination of the teaching of Japanese majors and the Internet from three aspects of teachers' teaching process, students' learning process and performance assessment, hoping to provide some direction for the Internet application of the teaching of Japanese majors.

\section{References}

[1] Meng Zhuo. Application of network resources in Japanese teaching. [J]. intelligence, 2015 (03): 94-95.

[2] Wang Xuan Li. Application of network resources in Japanese teaching. [J]. technology wind, 2014 (14): 220.

[3] Xu Jianming, Xiong Ping, Li Wei. Reflections on the construction of network resources in Japanese teaching [J]. science and technology information, 2012 (33): 751+602.

[4] Wu Hui, Yang Xiaohui. On the use of network resources in Japanese teaching [J]. Journal of Shenyang Normal University (SOCIAL SCIENCE EDITION), 2007 (01): 158-160.

[5] Wu Hong, Bai Xiaoguang, Gan Ling Qing, Yang Jiucheng. The application of network teaching system in Japanese Teaching -- Taking "Japanese primary reading" as an example, [J]. Journal of PLA Foreign Languages Institute, 2004 (03): 63-66.

[6] Li Dali, Qiu Wei. The development and characteristics of Japanese online course: Taking Japanese elementary course as an example, [J]. Japanese learning and research, 2003 (01): 57-61. 